Наталья Дранникова

navad@atknet.ru

\title{
Мифологические персонажи культурного пространства в севернорусском и норвежском фольклоре (типологические аспекты)
}

\begin{abstract}
Drannikova Natalia, Mifologičeskije personaži kulturnogo prostranstva $v$ severnorusskom i norvežskom folklore (tipologičeskije aspekty) (Mythological Characters of the Cultural Space in the Folklore of the Russian North and Norway [Typological Aspects]). „Poznańskie Studia Slawistyczne” 3. Poznań 2012. Adam Mickiewicz University Press, pp. 247-259. ISBN 978-83-232-2473-0. ISSN 2084-3011.

Mythological characters of the cultural space in the folklore of the Russian North and Norway (typological aspects) is a comparative analysis of spirits of house that exist in the cultures of both countries. For comparison, we examined different names, habitat, status and functions of spirits at home. For the first time in the scientific revolution a lot of original folk material is introduced.
\end{abstract}

Keywords: Russia, Norway, folklore, stories, house spirit, house, typological analysis

\section{Введение}

Статья посвящена исследованию представлений о духе-,хозяине” дома (домовом и ниссе) в народной культуре Архангельской области России и Северной Норвегии. Существование данных представлений в современной фольклорно-речевой практике подтверждают публикации полевых материалов, сделанные в последние годы, и материалы наших экспедиций в различные районы Архангельской области в период с 1990 по 2012 гг. и в Северную Норвегию (Финнмарк и Тромсе) в 2006-2007 гг.

* Работа выполнена при поддержке Российского гуманитарного научного фонда (проект № 11-14-29009, „Фольклор Архангельского Поморья как этнокультурный феномен”). 


\section{Вступление}

Изучением семантики и функционирования образов домашних духов-,,хозяев” занимались следующие исследователи: в Норвегии - Ю.К. Квигстад, Т. Стьюрорд, С. Солхейм, Л. Старк, и др. ${ }^{1}$, в России - Д.К. Зеленин, Э.В Померанцева, В.П. Зиновьев, Н.А. Криничная, Е.Н. Рачинская, И.А. Разумова, Н.В. Дранникова ${ }^{2}$.

Источники нашего исследования можно разделить на несколько групп:

- полевые записи, хранящиеся в архиве Центра изучения традиционной культуры Европейского Севера Северного Арктического федерального университета имени М.В. Ломоносова (далее - ЦИТКЕС САФУ),

- сборники фольклорных текстов Н.В. Дранниковой и И.А. Разумовой, Ю.К. Квигстада, Т. Стьюрорда, Л. Старка, Е.Н. Рачинской ${ }^{3}$,

- словари (мифологические, этнокультурные и диалектные),

- фольклористические, этнографические труды авторов, которые публикуют и цитируют интересующие нас тексты (труды С.В. Максимова, П.С. Ефименко, Д.К. Зеленина и др. ${ }^{4}$.

${ }^{1}$ J. Qvigstad, B. Pollan, Samiske beretninger: i utvalg fra J.K. Qvigstads „Samiske eventyr og sagn" I-IV, 1927-1929, Oslo 1997; T. Storjord, Lulesamiske eventyr og sagn, b. 2, Bodф Larerh $\phi$ gskoles Skriftserie, Oslo 1991; S. Solheim, Underjordsfolk, „Norveg” № 16, 1973, s. 148-333; L. Stærk, Eventyr og sagn fra Sør-Varanger?, Kárásjohka Davvi Girji 1994.

2 Д.К. Зеленин, Избранные труды. Очерки русской мифологии: Умершие неестественной смертью и русалки, вступ. статья Н.И. Толстого; подгот. текста, комм., указат. Е.Е. Левкиевской, Москва 1995; Э.В. Померанцева, Русская устная проза, Москва 1985; В.П. Зиновьев, Жанровые особенности быличек, Иркутск 1974; Н.А. Криничная, Русская народная мифологическая проза: Истоки и полисемантизм образов, т. 1: Былички, бывальщины, легенды, поверья о духах-,хозяевах”, Санкт-Петербург 2000; В стране троллей. Кто есть кто в норвежском фольклоре, сост. Е. Рачинская, перев. Н. Кулиниченко et al., Москва 2008; Мифологические рассказы Архангельской области, сост., авт. вступ. ст., комм. Н.В. Дранникова, И.А. Разумова; авт. подгот. текстов, указателей, словаря Н.В. Дранникова, Москва 2009.

${ }^{3}$ Мифологические рассказы Архангельской области; J. Qvigstad, op. cit.; L. Stærk, op. cit.; T. Storjord, op. cit.; В стране троллей...

${ }^{4}$ С.В. Максимов, Нечистая, неведомая и крестная сила, Санкт-Петербург 1903; Д.К. Зеленин, ор. cit. 
Работа выполнена в рамках синхронно-диахронного подхода к анализу исследуемого материала, записи которого охватывают более чем полуторавековой период. Первая фиксация мифологических рассказов в России была сделана в 1856 г. С.В. Максимовым, последние записи относятся к началу XXI в. Первые записи норвежских рассказов о ниссе были опубликованы в 1833 г. писателем А. Файе последние их записи относятся к 2006-2007 гг.

По отношению к рассказам о контактах человека с духами-,ххзяевами” в русской науке используются термины „устный рассказ”, „мифологический рассказ”, „быличка”. В Норвегии подобные рассказы называются сагн (sagn). Они являются сюжетно-оформленными историями или информативно-описательными текстами, повествующими о персонажах, наделенных демонической сверхъестественной силой, которых принято также называть представителями „низшей мифологии” или „нечистой силы”.

В жанровом аспекте быличку начала изучать Э.В. Померанцева, в работах которой отмечаются особенности бытования жанра мифологического рассказа в Европейской части России до середины XX в. Померанцева определяет быличку как,,суеверный рассказ о сверхъестественных существах и явлениях" ${ }^{\text {. }}$

Новые перспективы изучения быличек открыли исследователи, работающие в этнолингвистическом направлении. Так, Л.Н. Виноградова и С.М. Толстая создали „универсальную систему признаков, достаточную для идентификации любого мифологического персонажа в пределах славянского ареала"7, что позволяет провести сопоставительный анализ демонологических систем разных этнокультурных традиций. Итогом более чем векового изучения не только мифологии, но и этнографии, славянских языков, фольклора, народного искусства является этнолингвистический словарь Славянские древности ${ }^{8}$.

${ }^{5}$ Ibidem; F. Andreas, Folksagn, Christiania 1833.

6 Э.В. Померанцева, Жанровые особенности русских быличек, в: История, культура, фольклор и этнография славянских народов, Москва 1968, с. 274-292.

7 Л.Н. Виноградова, С.М. Толстая, К проблеме идентификачии и сравнения персонажей славянской мифологии, в: Славянский и балканский фольклор. Верования. Текст. Ритуал, Москва 1994, с. 16-42.

${ }^{8}$ Славянские древности: Этнолингвистический словарь, ред. Н.И. Толстой, Москва 1995-2009, т. 1: А-Г, т. 2: Д-К, т . 3: К-П, т. 4: П-С, т. 5: С-Я. 
Мифологическая проза имеет свою историю собирания, неотделимую от истории изучения. В последние десятилетия значительно увеличилось число записей мифологических рассказов. Этот факт отчасти можно связывать со снятием негласных запретов на собирание и изучение текстов, относящихся к религиозно-мифологической сфере. Если многие годы такой материал игнорировался собирателями, то сейчас он активно записывается. За последние двадцать лет участниками фольклорных экспедиций Московского государственного университета, САФУ (Архангельск), Института языка, литературы и истории РАН (Петрозаводск) и др. на территории Архангельской, Вологодской областей России и в Карелии было записано несколько тысяч быличек. Среди них рассказы о леших, домовых, водяных, колдовстве и контактах живых с умершими и др. Обилие подобного фольклорно-этнографического материала вряд ли следует связывать только с исследовательским интересом. Внимание к опыту общения со сверхъестественным характерно для человека, в какой бы исторический период он ни жил, при этом для каждой отдельной культуры (включая локальные ее варианты) в определенное время всегда можно установить факторы, поддерживающие „суеверные настроения” или, напротив, ослабляющие их. Что же касается Архангельского Севера, то собранный здесь на рубеже XX и XXI вв. фольклорно-этнографический материал, включающий мифологическую прозу, пока вполне способен подтвердить репутацию региона как „кладовой” севернорусской традиционной культуры. Эту ситуацию можно среди прочего объяснить относительной стабильностью сельского населения, хотя оно и весьма немногочисленно.

В 2009 году была издана книга Н.В. Дранниковой и И.А. Разумовой Мифологические рассказы Архангельской области, включающая в себя фольклорные записи ЦИТКЕС САФУ ${ }^{9}$ Тексты из этой книги отражают современное состояние архангельской локальной традиции жанра мифологических рассказов за последние 20 лет. Сопоставляя тексты последнего времени с более ранними, можно выявить как тенденции эволюции жанра, так и относительно стабильные его признаки, что в конечном итоге отражает особенности традиционного способа осознания и описания мира.

\footnotetext{
${ }^{9}$ Мифологические рассказы Архангельской области.
} 
Представления жителей Норвегии о мире и населявших его существах дошли до наших дней благодаря рукописи второй половины XIII века, получившей название Старшая Эдда. Самое полное отражение древнескандинавская мифология получила в книге исландского ученого, поэта С. Стурлусона Младщая Эдда. Но, как пишет исследовательница норвежского фольклора Е.Н. Рачинская, немногие фольклорные персонажи продолжают сохранять связь с героями мифа: „Миф - священный текст, он не допускает сомнения в своей истинности (...). События, отраженные именно в быличках, считали самыми правдивыми (...). Быличка - это как бы взгляд изнутри на то, чем и как жили норвеги до настоящего времени" ${ }^{\text {"10 }}$.

Первый публикатор норвежского фольклора А. Файе опубликовал несколько текстов о норвежском ниссе:

В старые времена ниссе было видимо-невидимо, не то что теперь. Почти в каждой усадьбе жил свой ниссе. Ростом они не больше ребенка, носят серые штаны, куртки и красные вязаные шапки с кисточкой. Пальцев у ниссе всего четыре, потому что больших пальцев на руках у них нет. Живут ниссе обычно на сеновалах, в хлеву или в конюшне (...) Они большие шутники: любят позабавиться, открыв стойла и выпустив коров на волю, или напугать скотницу $(. . .)^{11}$.

Приведенная цитата свидетельствует о существовании веры в мифологических духов-,,хозяев” в Норвегии XIX в., однако литературная обработка и пересказ первоисточников, сделанные А. Файе, существенно затрудняют выявление особенностей семантики и функционирования интересующего нас образа.

В 1841 г. П.К. Асбьернсен и Йоргенс Му издали Норвежские народные сказки ${ }^{12}$. В собраниях сказок П.К. Асбьернсена и Й. Му „как в капле воды, отражаются окружающая природа и жизнь Норвегии:

${ }^{10}$ В стране троллей..., с. 19.

${ }^{11}$ А. Файе, Норвежске предания, 1833, s.l.

${ }^{12}$ П.К. Асбьернсен, Норвежские народные сказки, Христиания 1841; П.К. Асбьернсен, Й. Му, На восток от солниа, на запад от луны: норвежские сказки, пересказ А. Любарской, П. Стравца, А. Шломиной, вступ ст. и коммент. О. Василиади, Москва 2012. 
леса и горы, глубоко врезающиеся в сушу фьорды (...) и, конечно, таинственные существа - тролли, хюльдры (горные ведьмы), ниссе (гномы) и эльфы",

Исследования в области фольклора Скандинавии продолжились в XX веке. Большую роль для изучения норвежской мифологической прозы имеет книга Ю.К. Квигстада ${ }^{14}$, где дается тематическая классификация фольклорного материала, записанного среди норвежских, шведских, финских и русских саамов. К исследованиям в области русского и норвежского фольклора относится статья Н.В. Дранниковой и Р. Ларсена Образ „чуди” в фольклоре народов Европейского Се$в$ ера ${ }^{15}$, которая является одним из первых опытов сравнительного анализа двух этнических традиций. Исследователи отмечают, что сюжеты о чуди (аборигенах, живших на территории Севера, до появления здесь русских) были распространены в различных местах, фиксировались в различное время и испытали влияние мифологической прозы о духах-,,хозяевах”. Следует отметить, что в русской фольклористике изучение мифологической прозы, в частности, быличек, совершалось параллельно с развитием фольклористики как науки. В Норвегии фольклорные тексты претерпевали сильное влияние литературной традиции, в частности, обработку текстов собирателями и различные изменения в содержании, что, безусловно, нашло отражение в дошедших до нас публикациях.

Большое значение для изучения норвежской традиции имеет словарь Дж. Линдоу Норвежская мифология: путь к богам, ритуалам и верованиям ${ }^{16}$. В нем дается характеристика мифологических персонажей по таким признакам, как внешний облик, функции, номинации и др. В словаре опубликован краткий пересказ поверий, связанных с тем или иным персонажем.

${ }^{13}$ Вся Норвегия на русском, ред. Н.В. Будур, <http://www.norge.ru/norske_grim broedre> [доступ: 5.10.2005].

${ }^{14}$ J. Qvigstad, B. Pollan, op. cit.

${ }^{15}$ Чудь в устной традиции Архангельского Севера, материалы и исследования, вступ. ст., сост, подгот. текстов, науч. аппарат Н.В. Дранниковой, Архангельск 2008.

${ }^{16}$ J. Lindow, Norse Mythology: A Guide to the Gods, Rituals, and Beliefs, <http://depositfiles.com/files/1wx82aok8> [доступ: 30.03.2012]. 


\section{Основная часть}

В процессе сравнения духов-,,хозяев” мы опирались на следующие признаки: название (номинация), происхождение, внешний облик, место обитания, время появления, статус, функции и отношения с человеком.

В Норвегии название духа-,,хозяина” дома и придомовых территорий - ниссе (nisse). Это название может варьироваться и присоединять к себе другие слова, манифестирующие особенности мифологического персонажа. Еще одно наименование ниссе - тункалл (дворовой мужичок). В группу имен, генетически связывающих норвежского домового с духом умершего предка, входит название хаугбонд (haugebonde) - бонд из кургана, также встречаются номинации: тамтегуббе, губонд (godbonde) - „хороший бонд”"17. Bonde в переводе с норвежского означает „фермер”, „хозяин земли”, ${ }^{2}$.

В архангельской традиции домовой чаще всего получает название по месту обитания (домовой, хозяин дома). В книге Н.В. Дранниковой и И.А. Разумовой присутствует 23 номинации домового, среди которых - домовеюшко-батюшко [№ 132] ${ }^{19}$, жихарь [№ 133], ботамушко, дедушко-соседушко [№ 134], дедушка [№ 140], ботоманушко [№ 149], домовейко [№ 146], доможилушко [№ 147]. Зафиксированы табуированные номинации домового: сам [№ 185], он [№ 187] и др. Названия домового отличаются в разных ареалах Архангельской области, например: в Устьянском районе - ботамушко, в Плесецком районе - жихарь и др. Высока степень эвфемизации в названиях: дедушко-соседушко, хозяин-домовой, хозяюшко. Семантика названия „домовой” связана со словом „дом”, но в ряде текстов она сужается (голбешник, запечник). Существует номинация кутамушко-мутамушко, образованная от слова „кут” - угол крестьянской избы ${ }^{20}$. Наряду с мужским образом домового существуют женские

${ }^{17}$ В стране троллей..., с. 95.

${ }^{18}$ J. Lindow, op. cit., s. 82.

19 Здесь и далее русские примеры текстов приводятся по книге: Мифологические рассказы Архангельской области, поэтому ссылка на саму книгу даваться не будет, указываются только номера текстов.

${ }^{20}$ В. Иванович, Даль. Толковый словарь живого великорусского языка, т. 3, Москва 2002, с. 230. 
парные соответствия этому персонажу: в одних случаях - это жена и дочь домового, в других - мифологические хозяйки дома, домовихи и суседки [№ 179]. В норвежском фольклоре подобного явления не наблюдается.

Основное сходство номинаций домового и ниссе в архангельской и норвежской традициях проявляется через топосы дома или домашнего пространства, уважительное отношение к духу дома передается в русской традиции через префиксы (-ко, -ушко, -ейко), в норвежской - через эпитеты (хороший, добрый и др.).

Обычно русский домовой считается умершим членом семьи, первопредком рода, который за грехи назначен Богом в услужение живым домочадцам; умершим без покаяния мужчиной и др. ${ }^{21}$. В отношениях домового и человека прослеживается связь между человеком и умершими членами семей [№ 187-193].

Ниссе, как и домовой, по народным верованиям, связан с миром предков. Следует отметить такую особенность норвежской традиции, как наличие родового древа этого персонажа. Оно представлено следующим образом: древний ниссе (VII в.), хранитель хутора (X в.); в этот же исторический период появляются корабельный, лесной и церковный ниссе, к XVI в относят образ рождественского ниссе. Трансформация от „хранителя” хутора в домового произошла уже в XI веке (еще одна номинация нисcе - bonde, что означает хранитель).

Определить точное происхождение образа домового сложно, тем не менее имеющиеся в нашем распоряжении тексты позволяют сделать вывод о том, что этот образ в севернорусской традиции связан как с культом огня / очага (местом обитания духа дома иногда является печь - об этом свидетельствуют названия печник, запечник) [№ 142], так и с культом предков (на это указывает сходство с покойным родственником; одежда домового, напоминающая похоронную и т.п.): „Стоит, весь в белом, рубаха, пояс, как прямо дед мой, покойный” [№ 185].

В некоторых севернорусских быличках домовой невидим и выступает как предвестник какого-либо трагического события (смерть,

\footnotetext{
${ }^{21}$ Славянские древности..., т. 2, с. 120.
} 
пожар и т.д.) [№ 176, 167, 168]. Чаще всего домовой имеет антропоморфный облик - это приземистый мужик с большой седой бородой, лохматый, обросший шерстью, с косматыми ладонями и подошвами, с длинными ногтями [№ 135, 136, 138, 175]. Зафиксировано появление домового в образе черного человека [№ 195]. В доме, где есть мужчины, домовой имеет вид мужчины; если в семье одни женщины и хозяйка дома -женщина, то домовой является в образе женщины [№ 159, 191]. В устных рассказах домовой имеет и зооморфную ипостась: он предстает в виде свиньи, птички [№ 139], собаки [№ 137], теленка [№ 138], кошки [№ 158] и пр. В архангельской традиции домовой существует в двух ипостасях: первый - живет дома, второй - во дворе и называется лаской. Наблюдается устойчивая вера в домового. Респонденты подробнее описывают домового-ласку. Этот персонаж оценивается, как правило, негативно, в отличие от домового. Он якобы похож на горностая, имеет шерсть, напоминающую яичный желток Он появляется в хлеве и на конюшне, мучает домашнюю скотину, заплетает лошадям косички, может загнать ее до пота / пены, завивает подстилку из сена. Считается, что избавиться от ласки можно с помощью козла или козлиной шкуры [№ 2002-202].

В норвежских сагн выделяются две разновидности образа домового / ниссе: антропоморфная (ниссе является перед людьми в образе старика небольшого роста [с. 95]), во многих текстах подчеркивается обилие волос на домовом, как правило, седого цвета. Его внешность прописана слабо, возможно, одежда ниссе не отличалось от традиционной норвежской одежды хозяина дома. Важной особенностью внешнего облика ниссе является наличие четырех пальцев на каждой руке [c. 97] $]^{22}$. Реже встречается нулевоморфная разновидность (домовой невидим) [с. 97]. Зооморфная ипостась ниссе нами не обнаружена.

Антропоморфность, зооморфность и нулевоморфность являются ключевыми признаками в классификации внешнего вида домового и ниссе. В русском и норвежском фольклоре выявлены общие для двух культур представления о домовом как о седом старике неболь-

22 Здесь и далее норвежские примеры текстов приводятся по книге: $B$ стране троллей..., поэтому ссылка на саму книгу даваться не будет, указываются только номера страниц. 
шого роста или лохматом существе, пол которого соответствовал полу хозяина. В архангельской традиции антропоморфность этого образа представлена шире по сравнению с норвежской (старик, старуха, черный человек, простой мужик, лохматое сущзество) [см., например, № 135, 136, 138, 175].

Только в архангельских рассказах дух дома имеет зооморфный облик и предстает в виде кошки, собаки и ласки; он невидим. Представления о локализации архангельского домового часто связываются с печью: он может жить за печкой, на печке, под печкой [№ 140, 151, 181]; местом его обитания может являться хлев [№ 155], погреб [№ 138], в некоторых текстах есть указание на то, что власть домового распространяется на все хозяйственные постройки [№ 132, 141].

Локусы, связанные с nisse, в доме - печь, угол дома, чердак. Норвежцы верили, что ниссе имеет свою особую комнату, которую нельзя никому занимать. Ниссе будто бы может обитать около дома под самым старым деревом, на хуторе [с. 98]. В норвежском фольклоре происходит отождествление домового и дворового: ниссе живет как в углах дома, так и в сушилах для рыбы и под деревьями [с. 101]. Таким образом, локализация духа дома в двух соседних культурах, прежде всего, связывается с печью / культом огня / домашнего очага, но возможны варианты проживания „домового”: на Русском Севере пространство около печи, подпол, чердак; в Норвегии - территории около дома (место под старым деревом).

Рассмотрим основные мотивы рассказов о домовом. В архангельских мифологических рассказах домовой имеет статус хозяина дома, покровителя семьи и скота. Считается, что он живет в каждом доме, является „сторожем дома” [№ 132, 141]. По народным представлениям, домовой „свой”, он не относится к „нечистой силе” [№ 184], часто он присутствует только акустически [№ 176]. Домовой выполняет все хозяйственные работы: вздувает и поддерживает огонь в печи, убирает дом, сушит зерно, ездит за водой, ухаживает за скотом [№ 134, 139].

Домовой считается хозяином-опекуном скота и птицы в доме. Если он любит скотину, то она становится гладкой, сытой, здоровой. Домовой подгребает корм в ясли, чистит скотину, расчесывает гриву лошади [№ 194, 204, 205, 207]. Масть скотины является главным фак- 
тором, влияющим на отношение домового к скотине, и если масть выбрана неправильно (,не по масти”), то домовой начинает „мучить скотину” [№ 194, 201, 202].

Один из широко распространенных мотивов - это предсказание будущего домовым. Домовой „давит” спящего человека, предсказывая в этот момент судьбу человека [№ 158, 163, 165, 168, 173]. Предвещая добро обитателям дома, он смеется, гладит мохнатой или теплой рукой; предвещая печальные события, особенно смерть кого-либо из домочадцев, он воет, стучит, хлопает дверями [№ 169, 171, 172]. Содержание предсказаний определяется ключевыми событиями жизненного цикла человека [№ 165]. В Северной Норвегии ниссе так же, как и русский домовой, следит за тем, чтобы коровы давали жирное молоко, убирает навоз, посыпает опилками пол в хлеву, доит коров и задает скоту корм [с. 99]. В норвежских рассказах, как и в севернорусской традиции, если домовой любит скотину, то она становится здоровой, плодовитой. Для норвежского домового не имеет значения масть скотины. Ниссе помогают в поле: косят сено, во время уборки хлеба обмалывают зерно, приходят на помощь в момент опасности [c. 100]. Пиво и сваренная на сливках или молоке каша является для ниссе главной наградой за труд (зафиксированы тексты, в которых упоминается ритуальное кормление ниссе - всего лишь один раз в год) [c. 101]. Ниссе может сам предложить свои услуги по хозяйству (в этот момент он появляется в виде маленького человечка в красной шапке) [с. 100]. Мотивов о его семье ниссе и предсказания им будущего не обнаружено. Часто в текстах указывается на необходимость соблюдения определенных правил в отношении ниссе, например: нельзя громко ругаться, притрагиваться к пище домового и т.п. [с. 106]. В норвежской традиции существует ритуальная практика не только „приглашения” домового на новое место, но и приглашение ниссе от одного хозяина к другому на более „выгодных условиях” [c. 106]. Можно передать ниссе „от брата к брату”, а можно выйти на перекресток и позвать его к себе [с. 103]. По различным причинам (плохое отношение к домашнему духу, отсутствие приношений и т.д.) домовой может выжить хозяина из дома или прогнать „чужого” человека, если он занял его локальное пространство [с. 98]. Норвежский дух дома имел право „наказывать ссорящихся” - от этого будто бы 
зависело благополучие семьи. Несоблюдение различных правил в отношении ниссе наказывалось. Зафиксированы тексты, где хозяин обижает ниссе „словом” и после этого ниссе покидает дом [с. 106-107].

В архангельских устных рассказах отношения в семье и ее благополучие зависят от расположения к ней домового. Прежде всего, это проявляется в соблюдении домашнего этикета, ритуальной практики „приглашения” домового при перемене жилища. Несоблюдение этой практики имеет отрицательные последствия [№ 144-150]. Домовой следит за порядком и местонахождением членов семьи, охраняет свой локус от вторжения как „чужих” людей, так и членов семьи; считается, что у домового следует просить разрешения на вход в дом [№ 151, 152, 155]. Существуют довольно редкие сюжеты о том, как домовой не пускает женщину замуж [№ 188] и как помогает человеку освободиться от тоски по умершему родственнику [№ 192].

\section{Заключение}

Подведем некоторые итоги нашего исследования. Исследование углубляет существующие в науке представления о традиционной культуре двух соседних стран - России и Норвегии. Анализ мифологических рассказов приводит нас к следующим выводам. Образ домового в севернорусской этнокультурной традиции типологически сходен с образом ниссе в норвежской традиции по ряду признаков и функций:

- по принципу номинации (наименования норвежского и русского духа дома образованы как от топоса дома и его внутреннего пространства, так и от приписываемого ему статуса хозяина дома),

- по локализации домашнего духа,

- по типам связи с жизнью хозяина дома,

- домовой и ниссе выполняют функцию покровителя семьи.

Можно говорить и о схожести генезиса обоих образов. Представления о домашних духах-,,хозяевах”, сложившиеся в ходе познавательной и хозяйственной деятельности человека (как в севернорусской, так и в норвежской культуре) стали одними из основополагающих в его мировоззрении - это культ предков и топос дома как 
сакральное, почитаемое место. Олицетворением этих мировоззренческих элементов в русской культуре стал домовой, в норвежской ниссе. Сопоставление структур мифологических рассказов приводит нас к выводу о том, что специфика текстов обнаруживается на уровне тематики - она изоморфна формам практики, свойственной культуре. Это практика земледельческая, хозяйственная, и вместе с тем социальная, связанная с имущественными отношениями. Именно различие норм и практик лежит в основе тематических различий и функций духов-,,хозяев” дома в севернорусской и норвежской фольклорных традициях. Кроме того, большую роль в представлениях о духах-,,хозяевах" играют ландшафтно-географические и этносоциальные особенности. Мифологические представления и способ репрезентации соответствующих знаний неотделимы от степени характера влияния профессиональной культуры („культурного ядра”) на народную, от развития и типов семейной культуры, от восприятия СМИ и многого другого, включая не поддающуюся объяснению традицию рассказывания в данной местности, или тип речевой культуры.

Образы домового и ниссе в данных фольклорных традициях имеют свои дифференциальные признаки, такие, как способы образования номинаций (префиксы, эпитеты), влияние различных природных условий и условий быта населения на локализацию домового, различие функций персонажа, а также различное отношение домового к членам семьи, связанное с домашним этикетом.

Сделанные нами наблюдения пока только намечают пути к более строгому и детальному изучению этнических особенностей и локальных вариаций данных мифологических персонажей. 
